\title{
ANALISIS PERENCANAAN DAN PENGENDALIAN BIAYA PEMELIHARAAN AKTIVA TETAP (MESIN) UNTUK MENJAGA KELANCARAN PRODUKSI PADA PT. TROPICA COCOPRIMA
}

\author{
Oleh: \\ Anggreanny Pratiwi Walukow \\ Agus Poputra \\ Harijanto Sabijono
Fakultas Ekonomi dan Bisnis, Jurusan Akuntansi
Universitas Sam Ratulangi Manado
email: walukowanggreanny@yahoo.com

\begin{abstract}
ABSTRAK
Penelitian ini merupakan studi kasus pada PT. Tropica Cocoprima dengan judul, "Analisis Perencanaan dan Pengendalian Biaya Pemeliharaan Aktiva Tetap (Mesin) Untuk Menjaga Kelancaran Produksi”. PT. Tropica Cocoprima adalah perusahaan yang menghasilkan tepung sebagai produk akhir dari proses produksi. Dalam proses produksi, mesin produksi memegang peranan penting dalam menghasilkan produk oleh karena itu sangat dibutuhkan perawatan agar terhindar dari sering terjadinya kerusakan. Penelitian ini bertujuan untuk menganalisis biaya rutin biaya pemeliharaan mesin dalam rangka perencanaan dan pengendalian pada PT. Tropica Cocoprima. Untuk merencanakan dan mengendalikan biaya perlu diadakannya pemisahan antara biaya variabel dan biaya tetap. Pada penelitian ini, digunakan metode kuadrat terkecil untuk memisahkan biaya tetap dan biaya vaiabel. Perhitungan dengan menggunakan analisis selisih varian yaitu analisis tiga selisih, didapati bahwa perusahaan mendapatkan selisih menguntungkan untuk biaya pemeliharaan mesin tetap yaitu pada selisih efisiensikarena unit yang diproduksi yaitu $1.750 .000 \mathrm{~kg}$ lebih besar dari unit yang direncanakan yaitu sebesar $1.166 .415 \mathrm{~kg}$.
\end{abstract}

Kata kunci : analisis perencanaan,pengendalian

\begin{abstract}
This researchwas case studyon PT. Tropica Cocoprima, the title is "Analysis of Planning and Contolling Maintenance Cost of Fixed Assets (Mechanical) To Maintain Smooth Production”. PT. Tropica Cocoprima is a company that produces flour as the end product of the production process. In the production process, production machinery plays an important rolein providing products there for eurgently needed care in order to avoid frequent damage. This purpose of research is to analysis routin cost of eengine maintenance cost for planning and control at PT. Tropica Cocoprima. To plan and controlling cost, need to the holding of separation between variable cost and fixed cost. This research used the least squares method for separate the variable cost and fixed cost. Calculations with using analysis three difference, was found that the companies getting difference inprofitable for costs maintenance of machine fixed namely on difference efficiency because the unit that produced is $1.750 .000 \mathrm{~kg}$ greater than the planned unit is $1.166 .415 \mathrm{~kg}$.
\end{abstract}

Keywords : analysis planning,control 


\section{Latar Belakang}

\section{PENDAHULUAN}

Suatu perusahaan agar dapat mempertahankan aktivitas operasi dan manajemen yang baik, maka harus terus melakukan perbaikan dari periode ke periode. Perbaikan itu diantaranya adalah mutu produk, inovasi, ketepatan waktu saat produksi, dan memangkas biaya yang tidak perlu terjadi. Perolehan laba sangat ditentukan oleh pendapatan yang diperoleh, dan biaya yang harus dikeluarkan untuk memperoleh pendapatan tersebut. Oleh karena itu, maka perencanaan dan pengendalian biaya mutlak diperlukan agar tidak terjadi pemborosan. Pengeluaran biaya tersebut benar-benar diarahkan untuk memperoleh pendapatan yang diharapkan dari tahun ke tahun terjadi peningkatan seiring dengan pertumbuhan perusahaan. Perencanaan dan pengendalian biaya memiliki peranan yang besar bagi perusahaan. Proses perencanaan akan memberikan arah atau dapat dijadikan sebagai pedoman bagi kegiatan-kegiatan operasional perusahaan, sedangkan pengendalian akan menjamin terjadinya keselarasan antara tujuan-tujuan dan rencana perusahaan. Perencanaan dan pengendalian akan sangat membantu dan bermanfaat bagi perusahaan agar dapat beroperasi secara efisien dan efektif, dimana kondisi ini akan mempengaruhi tingkat keuntungan yang diperoleh perusahaan.

PT. Tropica Cocoprima merupakan perusahaan yang memproduksi tepung yang mempunyai banyak mesin dalam kegiatan produksinya yaitu untuk mengubah bahan baku yaitu kelapa menjadi produk jadi yang siap untuk dijual. Mesin-mesin yang digunakan akan mengalami kerusakan jika tidak adanya kegiatan pemeliharaan dan hal ini bisa mengganggu jalannya proses produksi. Tentu saja kegiatan pemeliharaan atau perawatan mesin akan berjalan dengan efektif dan efisien jika manajemen bisa merencanakan dan mengendalikan biaya yang akan dikeluarkan dengan tepat, sehingga penulis tertarik untuk melakukan penelitian tentang perencanaan dan pengendalian biaya pemeliharaan aktiva tetap (mesin) untuk menjaga kelancaran produksi pada PT. Tropica Cocoprima.

\section{Tujuan Penelitian}

Untuk menganalisis biaya rutin pemeliharaan mesin dalam rangka perencanaan dan pengendalian pada PT. Tropica Cocoprima.

\section{Pengertian Biaya}

\section{TINJAUAN PUSTAKA}

Carter (2009:30) yang diterjemahkan oleh Krista, menyatakan bahwa biaya adalah suatu nilai tukar, pengeluaran, atau pengorbanan yang dilakukan untuk menjamin perolehan manfaat. Mulyadi (2009: 23),menyatakan bahwa biaya adalah pengorbanan sumber ekonomi, yang diukur dalam satuan uang, yang telah terjadi atau yang kemungkinan akan terjadi untuk tujuan tertentu. Prawironegoro dan Purwanti(2008: 49),menyatakan biaya adalah kas dan setara kas yang dikorbankan untuk memproduksi dan memperoleh barang atau jasa yang diharapkan akan memperoleh manfaat atau keuntungan dimasa mendatang. Selanjutnya Widilestariningtyas, dkk (2010:10), menyatakan bahwa biaya adalah biaya sebagai nilai tukar, pengeluaran, pengorbanan untuk memperoleh manfaat.

\section{Pengertian dan Tujuan Pemeliharaan Mesin}

Setiawan (2008:12), menyatakan bahwa pemeliharaan adalah tindakan merawat mesin atau peralatan pabrik dengan memperbaharui umur masa pakai dan kegagalan/kerusakan mesin. Tujuan pemeliharaan yang utama dapat didefenisikan sebagai berikut.

a. untuk memperpanjang kegunaan asset,

b. untuk menjamin ketersediaan optimum peralatan yang dipasang untuk produksi dan mendapatkan laba investasi maksimum yang mungkin, 3

c. untuk menjamin kesiapan operasional dari seluruh peralatan yang diperlukan dalam keadaan darurat setiap waktu,

d. untuk menjamin keselamatan orang yang menggunakan sarana tersebut.

\section{Perencanaan dan Pengendalian Biaya}

Dharmanegara (2010:5), menyatakan bahwa perencanaan diperlukan agar perusahaan dapat mengoperasikan departemen dan mencapai keberhasilan segmen. Ini melihat kepada apa yang harus dilakukan, bagaimana ini harus dilakukan, kapan ini harus dilakukan, oleh siapa. Carter (2009:5), menyatakan bahwa terdapat tiga jenis rencana yang dapat diidentifikasikan dalam entitas bisnis yaitu rencana strategik, rencana jangka pendek, dan rencana jangka panjang. Nafirin (2007:4), menyatakan bahwa perencanaan merupakan 
tindakan yang dibuat berdasarkan fakta dan asumsi mengenai gambaran kegiatan yang akan dilakukan di masa mendatang untuk mencapai tujuan yang diinginkan.

Rencana strategik diformulasikan di tingkat manajemen tertinggi, memerlukan pandangan luas atas perusahaan dan lingkungannya, paling tidak dapat diukur, dan diformulasikan pada interval waktu yang tidak teratur melalui proses yang pada dasarnya tidak sistematis, yang dimulai dengan pengidentifikasian kesempatan atau ancamaneksternal. Rencana jangka pendek, seringkali disebut anggaran, cukup terperinci guna memungkinkan disusunnya laporan keuangan proforma bagi entitas tersebut untuk suatu periode di masa depan (biasanya akhir dari periode anggaran). Rencana ini disusun melalui proses sistematis, sangat terukur, dinyatakan dalam ukuran finansial, terutama fokus pada perusahaan itu sendiridengan menganggap bahwa lingkungan eksternal seperti apa adanya, dan biasanya dipersiapkan untuk periode bulanan, kuartalan, atau tahunan. Selanjutnya, rencana jangka panjang atau anggaran jangka panjang, biasanya mencakup periode tiga sampai lima tahun ke depan. Dalam hal tingkat rincian dan keterukuran, rencana jangka panjang berada di antara rencana jangka pendek dan rencanan strategik.

Selain perencanaan biaya, aktivitas pengendalian biaya juga mempunyai peran yang penting bagi perusahaan. Carter (2009:6), menyatakan bahwa pengendalian adalah usaha sistematis manajemen untuk mencapai tujuan. Aktivitas dimonitor secara kontinu untuk memastikan bahwa hasilnya akan berada dalam batasan yang diinginkan. Dharmanegara (2010:108), menyatakan bahwa perencanaan dan pengendalian dari item overhead memiliki dua tujuan utama yaitu sebagai berikut:

1. Untuk memperkecil biaya umum di manapun mereka terjadi

2. Untuk memastikan bahwa biaya overhead dialokasikan, dalam hal kebanyakan masalah akurasi, terhadap berbagai pekerjaan dan produk telah dibuat.

\section{Penelitian Terdahulu}

Tabel 1 Penelitian Terdahulu

\begin{tabular}{|c|c|c|c|c|c|c|}
\hline $\begin{array}{l}\text { Nama/ } \\
\text { Tahun }\end{array}$ & Judul & Tujuan & Metode & Hasil & Persamaan & Perbedaan \\
\hline $\begin{array}{l}\text { Wijayanti/ } \\
2008\end{array}$ & $\begin{array}{l}\text { Analisis } \\
\text { perencanaan } \\
\text { dan } \\
\text { pengendalian } \\
\text { biaya } \\
\text { pemeliharaan } \\
\text { mesin dan } \\
\text { instalasi } \\
\text { pada PG. } \\
\text { Kebon } \\
\text { Agung. }\end{array}$ & $\begin{array}{l}\text { Bertujuan } \\
\text { untuk } \\
\text { menganalisis } \\
\text { pengendalian } \\
\text { biaya } \\
\text { pemeliharaan } \\
\text { mesin dan } \\
\text { instalasi PG. } \\
\text { Kebon } \\
\text { Agung. }\end{array}$ & Deskriptif & $\begin{array}{l}\text { Hasil varians melaporkan bahwa tingkat } \\
\text { efisiensi yang tidak maksimal karena } \\
\text { tingkat sumberdaya manusia yang masih } \\
\text { rendah dan juga untuk membuat rencana } \\
\text { anggaran pada staf TUK tidak diimbangi } \\
\text { dengan faktor eksternal seperti tingkat } \\
\text { inflasi. }\end{array}$ & $\begin{array}{l}\text { Peneliti } \\
\text { sebelumnya } \\
\text { menguraikan } \\
\text { faktor yang } \\
\text { sama yaitu } \\
\text { perencanaan } \\
\text { biaya } \\
\text { pemeliharaan } \\
\text { mesin. }\end{array}$ & $\begin{array}{l}\text { Penelitian } \\
\text { sebelumnya } \\
\text { mengendalikan } \\
\text { dengan } \\
\text { menggunakan } \\
\text { analisis empat } \\
\text { varians } \\
\text { sedangkan } \\
\text { pada penelitian } \\
\text { ini } \\
\text { menggunakan } \\
\text { analisis tiga } \\
\text { selisih. }\end{array}$ \\
\hline $\begin{array}{l}\text { Artiningrum } \\
/ 2003\end{array}$ & $\begin{array}{l}\text { Evaluasi } \\
\text { perencanaan } \\
\text { dan } \\
\text { pengendalian } \\
\text { biaya } \\
\text { pemeliharaan } \\
\text { aktiva tetap } \\
\text { (mesin) pada } \\
\text { PG. Krebet } \\
\text { Baru } \\
\text { Bululawang }\end{array}$ & $\begin{array}{l}\text { untuk } \\
\text { mengevaluasi } \\
\text { pelaksanaan } \\
\text { perencanaan } \\
\text { dan } \\
\text { pengendalian } \\
\text { biaya } \\
\text { pemeliharaan } \\
\text { mesin yang } \\
\text { dilaksanakan } \\
\text { oleh PG. } \\
\text { Krebet Baru } \\
\text { Bululawang }\end{array}$ & Des & $\begin{array}{l}\text { Hasil perhitungan dengan menggunakan } \\
\text { analisis selisih, untuk selisih terkendali } \\
\text { pada tahun } 1999 \text { yang terjadi adalah selisih } \\
\text { yang tidak menguntungkan, sedangkan } \\
\text { pada tahun } 2000 \text { adalah selisih yang } \\
\text { menguntungkan. } \\
\text { Untuk tahun } 1999 \text { dan } \\
2000 \text { selisih volume } \\
\text { yang terjadi adalah selisih menguntungkan. } \\
\text { Pada analisis tiga selisih diketahui selisih } \\
\text { pengeluaran yang terjadi pada tahun } 1999 \\
\text { adalah selisih yang tidak menguntungkan, } \\
\text { sedangkan pada tahun 2000 selisih } \\
\text { pengeluaran yang terjadi adalah selisih } \\
\text { yang menguntungkan. Kemudian untuk } \\
\text { selisih efisiensi yang terjadi pada tahun } \\
1999 \text { dan2000 adalah selisih yang } \\
\text { menguntungkan. }\end{array}$ & $\begin{array}{l}\text { Melakukan } \\
\text { penelitian } \\
\text { pada faktor } \\
\text { yang sama } \\
\text { yaitu } \\
\text { perencanaan } \\
\text { biaya } \\
\text { pemeliharaan } \\
\text { mesin. }\end{array}$ & $\begin{array}{l}\text { Penelitian } \\
\text { sebelumnya } \\
\text { melakukan } \\
\text { evaluasi dalam } \\
\text { perncanaan } \\
\text { dan } \\
\text { pengendalian } \\
\text { biaya } \\
\text { pemeliharaan } \\
\text { sedangkan } \\
\text { peneliti } \\
\text { melakukan } \\
\text { analisis data } \\
\text { dalam } \\
\text { merencanakan } \\
\text { biaya } \\
\text { pemeliharaan } \\
\text { mesin. } \\
\end{array}$ \\
\hline
\end{tabular}




\section{Jenis dan Sumber Data}

\section{METODE PENELITIAN}

\section{Jenis Data}

1. Data kuatitatif yang digunakan dalam penelitian ini adalah biaya pemeliharaan mesin yang diperoleh dari objek penelitian, yaitu PT. Tropica Cocoprima

2. Data kualitatif yang digunakan dalam penelitian ini adalah struktur organisasi.

\section{Sumber Data}

1. Data Primer, merupakan data yang diperoleh dari sumber aslinya, data primer ini berupa hasil wawancara dengan manajer personalia dan staf bagian keuangan PT. Tropica Cocoprima.

2. Data Sekunder, merupakan data yang diperoleh dari pihak luar obyek penelitian yang berasal dari hasil penelitian kepustakaan, literatur kuliah, makalah, jurnal, majalah dan koran serta literatur-litreratur lainnya yang berhubungan dengan topik penelitian ini.

\section{Prosedur Penelitian}

1. Mengambil data biaya pemeliharaan mesin, pada PT. Tropica Cocoprima tahun 2011 dan 2012

2. Memisahkan biaya tetap dan biaya variabel dalam biaya pemeliharaan mesin

3. Menggunakan analisis selisih varian untuk mengetahui selisih kerugian dan keuntungan pada biaya pemeliharaan mesin

\section{Teknik Pengumpulan Data}

1. Survei Lapangan, dimana peneliti melakukan pengamatan dan pencatatan langsung ke objek penelitian untuk mendapatkan dan mencatat data-data yang diperlukan, dalam hal ini tentang biaya pemeliharaan mesin pada PT. Tropica Cocoprima.

2. Studi Kepustakaan, dimaksudkan untuk mendapatkan data yang sifatnya teoritis melalui penelaahan pada teori-teori yang telah dipelajari serta mencari sumber-sumber lain berdasarkan kepustakaan.

3. Dokumentasi, untuk memperoleh data-data dengan berdasarkan sejumlah dokumen-dokumen dan laporanlaporan tertulis yang dimiliki oleh PT. Tropica Cocoprima, khususnya yang berkaitan dengan biaya pemeliharaan mesin tahun 2011 dan 2012.

\section{Metode Analisis}

Metode analisis yang digunakan dalam pengolahan data adalah least squares method atau metode kuadrat terkecil untuk memisahkan biaya variabel dan biaya tetap. Kemudian analisis data selanjutmya yaitu dengan menggunakan metode analisis tiga selisih.

\section{Gambaran Umum}

\section{HASIL PENELITIAN DAN PEMBAHASAN}

PT. Tropica Cocoprima adalah perusahaan dalam negeri yang konsisten dengan memproduksi tepung kelapa sejak awal berdirinya perusahaan. Pabrik ini dibangun pada tahun 1997dan mulaioperasi komersialpada bulan Mei1998.Sebanyak278personelbekerjadan kapasitaspabrik adalah275MTper bulanDC. Filosofi perusahaanselaluuntuk memproduksi dan memasokproduk-produkberkualitasyangaman dikonsumsi manusia.

Perusahaan terletak di wilayah kelapa hasil tinggi Indonesia dan dilengkapi dengan keadaan fasilitas seni manufaktur. Produk kami diproses secara higienis dibawah control kualitas yang ketat dan operasi kami diawaki oleh personil yang berpengalaman, berdedikasi dan professional. Kami memiliki laboratorium sendiri, Independen kami di pabrik di mana pengujian baik bahan baku dan produk jadi dilakukan.

\section{Visi dan Misi}

1. Adapun visi perusahaan adalah Our vision to be rocognized and respected as one of the premier high-quality Desiccated Coconut Producer (visi kami adalah untuk dikenal dan diakui sebagi salah satu penghasil (produsen) Tepung Kelapa yang berkualitas tinggi)

2. Dan misi perusahaan adalah PT. Tropica Cocoprima is committed to supplying the consumer and our costumer with finest high-quality sesiccated coconut products and be profitable in the process. PT. Tropica Cocoprima supports this goal with a corporate philosophy of adhering to highest ethical conduct in all its business dealings, treatment of its employees, social and environmental policies (PT. Tropica Cocoprima berkomitmen untuk menjadi pemasok produk Tepung Kelapa yang terbaik dan berkualitas tinggi kepada para 
konsumen dan dengan proses yang menguntungkan. PT.Tropica Cocoprima mendukung tujuan ini dengan filosofi perusahaan yang menjunjung tinggi semua etika bisnis yang berlaku, mencakup perilaku karyawan, sosial dan kebijakan lingkungan).

\section{Hasil Penelitian \\ Mesin Produksi}

Perusahaan membutuhkan mesin produksi untuk mengolah bahan baku yang digunakan untuk membantu tenaga kerja dalam menghasilkan output yang diharapkan dalam menunjang kegiatan produksinya. Mesin produksi yang digunakan oleh PT. Tropica Cocoprima adalah sebagai berikut:

1. Bagian Opening

a. Mesin Nuts Cunter, untuk mengangkut kelapa biji ke box-box sheller.

b. Mesin Sheller, mesin yang dipakai untuk mengupas tempurung dari kelapa.

c. Mesin Conveyor tempurung, untuk mengangkut tempurung-tempurung yang sudah dikupas dari kelapa.

d. Mesin Conveyer kelapa putih, untuk mengangkut daging kelapa putih yang sudah dikupas kulit arinya masuk ke bagian Wet.

2. Bagian Wet

a. Mesin-mesin Screw-Daging Kelapa Putih (DKP) yang dari opening diangkut ke bagian penampungan DKP. Dari penampungan DKP ke tretment bak 5 di bak 5 ada mesin yang menunjukkan Screw untuk menaikkan DKP ke grinder (penggilingan).

3. Bagian Grinder

a. Mesin Grinder, untuk menggiling DKP menjadi White Meet kemudian menuju mesin blancher alat untuk mematikan kuman/ bakteri.

4. Bagian Dryer

a. Mesin Dryer, untuk pengeringan White Meet

b. Mesin Rotex, untuk memisahkan produk yang dihasilkan

c. Mesin pengepakan, produk akan siap untuk di packing sesuai ukuran produk.

5. Mesin Boiler, mesin yang mengubah air menjadi panas atau steam. Air panas atau steam dengan tekanan tertentu kemudian digunakan untuk mengalirkan panas pada proses produksi.

\section{Biaya Pemeliharaan Mesin}

Perusahaan membutuhkan biaya untuk kelancaran operasionalnya. Salah satu biaya yang penting bagi perusahaan adalah biaya pemeliharaan mesin yang adalah biaya menyangkut usaha-usaha untuk menghilangkan kemungkinan-kemungkinan yang menimbulkan kemacetan yang disebabkan karena kondisi fasilitas produksi yang tidak baik. Biaya pemeliharaan mesin yang terjadi pada tahun 2011 adalah sebesar Rp. 109.545.000,00 dengan jam kerja mesin yaitu 3.168 jam. Selanjutnya pada tahun 2012 biaya pemeliharaan mesin adalah sebesar 133.545.000,00 dan jam kerja mesin adalah 3.516 jam.

\section{Pembahasan \\ Analisis Perencanaan Biaya Pemeliharaan Mesin}

Tujuan proses anggaran adalah untuk mengarahkan pernyataan tujuan umum ke fokus perencanan biaya pemeliharaan aktiva tetap atau dalam hal ini lebih di khususkan kepada mesin produksi. Pihak manajemen harus melaksanakan kepemimpinan pada tahap perencanaan ini agar ada kerangka kerja yang nyata, jelas dan realistis dalam operasi yang akan dilaksanakan untuk pencapaian sasaran yang bersifat khusus. Hal ini akan memberikan suatu dasar bagi pengukuran kinerja.

Biaya variabel harus dipisahkan dengan biaya tetap untuk keakuratan hasil keputusan, untuk mengambil suatu keputusan yang memuaskan bagi perencanaan biaya pemeliharaan mesin dalam perusahaan. Data tahun 2011 akan menjadi standar atau patokan anggaran untuk menganalisis biaya perencanaan pemeliharaan mesin di tahun 2012. Penulis menggunakan metode analisis kuadrat terkecil (dengan bantuan Microsoft Excel 2010) untuk memisahkan biaya variabel dan biaya tetap, yang akan diuraikan pada tabel 2 .

Carter (2009:77), metode kuadrat terkecil (least squares method), kadang kala disebut analisis regresi, menentukan secara matematis garis yang paling sesuai, atau garis regresi linear, melalui sekelompok titik.

Biaya variabel, $b$, dapat dihitung sebagai berikut.

$$
\mathrm{b}=\frac{\sum(\mathrm{xi}-\mathrm{x})(\mathrm{y} 1-\mathrm{y})}{\sum(\mathrm{xi}-\mathrm{x})^{2}}=\frac{\text { total kolom } 6}{\text { total kolom } 5}
$$


Biaya tetap, $a$, dapat dihitung menggunakan rumus untuk garis lurus sebagai berikut. $\mathrm{y}=\mathrm{a}+\mathrm{bx}$

Tabel 2 Perhitungan Biaya Pemeliharaan Mesin

\begin{tabular}{|c|c|c|c|c|c|c|}
\hline & (1) & (2) & (3) & (4) & (5) & (6) \\
\hline & Y1 & $(\mathrm{Y} 1-\mathrm{Y}) \mathrm{X} 1$ & $(\mathrm{X} 1-\mathrm{X})$ & & & \\
\hline Bulan & $\begin{array}{c}\text { Biaya } \\
\text { Pemeliharaan }\end{array}$ & $\begin{array}{c}\text { Selisih dari } \\
\text { Rata-rata } \\
\text { Biaya Rp. } \\
\text { 9.128.750,00 }\end{array}$ & $\begin{array}{l}\text { Jam } \\
\text { Kerja } \\
\text { Mesin }\end{array}$ & $\begin{array}{c}\text { Selisih } \\
\text { dari } \\
\text { Rata- } \\
\text { rata } \\
264 \\
\text { Jam } \\
\end{array}$ & $\begin{array}{c}\text { (4) } \\
\text { Dikuadrat- } \\
\text { kan }\end{array}$ & (4)x(2) \\
\hline Januari & $4.800 .000,00$ & $(4.328 .750,00)$ & 138 & (126) & 15.876 & $545.422 .500,00$ \\
\hline Febuari & $10.570 .000,00$ & $1.441 .250,00$ & 128 & (136) & 18.496 & $(196.010 .000,00)$ \\
\hline Maret & $12.150 .000,00$ & $3.021 .250,00$ & 349 & 85 & 7.225 & $256.806 .250,00$ \\
\hline April & $8.350 .000,00$ & $(778.750,00)$ & 286 & 22 & 484 & $(17.132 .500,00)$ \\
\hline Mei & $10.100 .000,00$ & $971.250,00$ & 318 & 54 & 2.916 & $52.447 .500,00$ \\
\hline Juni & $12.150 .000,00$ & $3.021 .250,00$ & 349 & 85 & 7.225 & $256.806 .250,00$ \\
\hline Juli & $7.430 .000,00$ & $(1.698 .750,00)$ & 271 & 7 & 49 & $(11.891 .250,00)$ \\
\hline Agustus & $7.605 .000,00$ & $(1.523 .750,00)$ & 274 & 10 & 100 & $(15.237 .500,00)$ \\
\hline September & $12.300 .000,00$ & $3,171,250.00$ & 251 & (13) & 169 & $(41.226 .250,00)$ \\
\hline Oktober & $8.620 .000,00$ & $(508,750.00)$ & 264 & - & - & - \\
\hline November & $8.350 .000,00$ & $(778,750.00)$ & 286 & 22 & 484 & $(17.132 .500,00)$ \\
\hline Desember & $7.120 .000,00$ & $(2,008,750.00)$ & 254 & (10) & 100 & $20.087 .500,00$ \\
\hline Jumlah & 109.545.000,00 & - & 3.168 & - & 53.124 & $832.940 .000,00$ \\
\hline
\end{tabular}

Sumber : hasil olahan penulis

\section{Analisis Pengendalian Biaya Pemeliharaan Mesin}

Analisis selisih dibutuhkan dalam rangka untuk menetapkan penyebab terjadi selisih biaya, dan mengoreksi situasi yang merugikan. Dalam biaya pemeliharaan mesin dimungkinkan terjadi selisih, karena situasi atau standar yang tidak tepat sehingga terjadi lebih tinggi atau lebih rendah dari situasi yang sesungguhnya terjadi. Mursyidi (2007:264), menyatakan bahwa proses penyusunan BOP standar sama dengan perhitungan BOP pada sistem normal (normal costing system) yang membedakan antara normal costing system dan standard costing system adalah bahwa dalam normal costing system membebankan BOP ke produk berdasarkan kapasitas sesungguhnya, sedangkan pada sistem biaya standar, BOP dibebankan ke produk berdasarkan kapasitas standar.

Penelitian ini, akan digunakan data tahun 2011 sebagai patokan biaya atau standar sebagaimana yang telah di jelaskan sebelumnya pada analisis perencanaan biaya pemeliharaan mesin dan akan digunakan dalam metode analisis tiga selisih. Untuk tahun 2011 yang merupakan patokan atau standar perencanaan dan pengendalian biaya, jumlah output yang dihasilkan perusahaan adalah sebanyak $1.750 .000 \mathrm{~kg}$. Selanjutnya pada tahun 2012, perusahaan menghasilkan output sebanyak $1.166 .415 \mathrm{~kg}$.

a. Untuk biaya pemeliharaan mesin variabel

a) Selisih tarif biaya pemeliharaan mesin variabel 
(Tarif standar - tarif aktual) x Jam standar

$=($ Rp. 109.545.000,00 $-133.545 .000,00) \times 3.168$

$=-76.032 .000 .000,00$ (rugi)

b) Selisih Efisiensi

(jam standar - jam aktual) $x$ tarif standar

$=(3.168-3.516) \times 109.545 .000,00$

$=-38.121 .660 .000,00$ (rugi)

c) Selisih tarif dan efisiensi

(jam standar - jam aktual) x (tarif standar - tarif aktual)

$=(3.168-3.516) \times(109.545 .000-133.545 .000)$

$=-348 \times-24.000 .000$

$=-8.352 \cdot 000.000,00$

b. Untuk biaya pemeliharaan mesin tetap

a) Selisih tarif biaya pemeliharaan mesin tetap

(tarif standar - tarif aktual) x aktual output (unit)

$=($ Rp. 109.545.000,00 - 133.545.000,00) x $1.166 .415 \mathrm{~kg}$

$=-27.993 .960 .000 .000,00$ (rugi)

b) Selisih Efisiensi

(standar unit yang diproduksi - aktual unit) $\mathrm{x}$ tarif standar

$=(1.750 .000-1.166 .415) \times 109.545 .000$

$=583.585 \times 109.545 .000$

$=63.928 .818 .825 .000$ (laba)

c) Selisih tarif dan efisiensi

(standar unit yang diproduksi - aktual unit) x (tarif standar -tarif aktual)

$=(1.750 .000-1.166 .415) \times($ Rp. 109.545.000,00 - 133.545.000,00)

$=583.585 \times-24.000 .000$

$=-14.006 .040 .000 .000$

Berdasarkan hasil perhitungan dengan menggunakan analisis tiga selisih di atas, maka perhitungan selisih biaya pemeliharaan mesin dapat diuraikan sebagai berikut.

a. Untuk biaya pemeliharaan mesin variabel terdapat selisih kerugian pada tarif biaya pemeliharaan mesin variabel, selisih efisiensi, dam selisih tarif dan efisiensi selisih kerugian ini diakibatkan karena yang biaya sesungguhnya terjadi atau biaya aktual lebih besar daripada rencana yang telah ditetapkan.

b. Untuk biaya pemeliharaan mesin tetap, terdapat juga selisih kerugian pada perhitungan selisih tarif biaya pemeliharaan tetap dan selisih tarif dan efisiensi. Seperti pada biaya pemeliharaan mesin variabel, selisih kerugian diakibatkan oleh karena biaya aktual lebih besar dibandingkan rencana biaya direncanakan. Namun untuk perhitungan selisih efisiensi terdapat selisih menguntungkan karena standar unit yang diproduksi lebih besar daripada aktual unit sesungguhnya.

\section{Usulan Perencanaan Biaya Pemeliharaan Mesin}

Analisis regresi yang menggunakan rumus untuk garis lurus $\mathrm{Y}=\mathrm{a}+\mathrm{bx}$ digunakan dalam merencanakan biaya pemeliharaan mesin untuk periode tahun 2013. Usulan perencanaan biaya pemeliharaan mesin akan diuraikan pada tabel berikut ini. 
Tabel 3 PT. Tropica Cocoprima Usulan Perencanaan Biaya Pemeliharaan Mesin Tahun 2013

\begin{tabular}{|c|c|c|c|c|}
\hline Bulan & $\begin{array}{c}\text { Biaya } \\
\text { Pemeliharaan (Y) }\end{array}$ & $\mathbf{X}$ & X. Y & $\mathbf{X}^{2}$ \\
\hline Januari & $6,800,000.00$ & -5 & $(34,000,000.00)$ & 25 \\
\hline Febuari & $12,570,000.00$ & -4 & $(50,280,000.00)$ & 16 \\
\hline Maret & $14,150,000.00$ & -3 & $(42,450,000.00)$ & 9 \\
\hline April & $10,350,000.00$ & -2 & $(20,700,000.00)$ & 4 \\
\hline Mei & $12,100,000.00$ & -1 & $(12,100,000.00)$ & 1 \\
\hline Juni & $14,150,000.00$ & 0 & - & 0 \\
\hline Juli & $9,430,000.00$ & 1 & $9,430,000.00$ & 1 \\
\hline Agustus & $9,605,000.00$ & 2 & $19,210,000.00$ & 4 \\
\hline September & $14,300,000.00$ & 3 & $42,900,000.00$ & 9 \\
\hline Oktober & $10,620,000.00$ & 4 & $42,480,000.00$ & 16 \\
\hline November & $10,350,000.00$ & 5 & $51,750,000.00$ & 25 \\
\hline Desember & $9,120,000.00$ & 6 & $54,720,000.00$ & 36 \\
\hline Jumlah & 133,545,000.00 & & 60,960,000.00 & 146 \\
\hline
\end{tabular}

$\mathrm{a}=\frac{\sum \mathrm{Y}}{\mathrm{N}}=\frac{133,545,000.00}{12}=\mathrm{Rp} \cdot 11.128 .750,00$

$\mathrm{b}=\frac{\sum \mathrm{XY}}{\sum \mathrm{X}^{2}}=\frac{60,960,000.00}{146}=\mathrm{Rp} \cdot 417.534,24$

$\mathrm{Y}=\mathrm{a}+\mathrm{bx}$

Yjanuari2013 = Rp. 11.128.750,00+ Rp. 417.534,24 (7)

$=$ Rp. $11 \cdot 128.750,00+$ Rp. $2.922 \cdot 739,68$

$=$ Rp. $14,051,489.68$

Yfebuari2013 = Rp. 11.128.750,00+Rp. 417.534,24 (8)

$=$ Rp. $11 \cdot 128 \cdot 750,00+$ Rp. 3.340.273,92

$=$ Rp. 14.469.023,92

Ymaret2013 = Rp. 11.128.750,00+ Rp. 417.534,24 (9)

$=$ Rp. $11 \cdot 128 \cdot 750,00+$ Rp. $3 \cdot 757.808,16$

$=$ Rp. 14,886,558.16

Yapril2013 = Rp. 11.128.750,00+ Rp. 417.534,24 (10)

$=$ Rp. 11.128.750,00 + Rp. 4.175.342,40

$=$ Rp. 15.304.092,40

Ymei2013

$=$ Rp. 11.128.750,00 + Rp. 417.534,24 (11)

$=$ Rp. 11.128.750,00 + Rp. 4.592.876,64

$=$ Rp. 15.721.626,64

Yjuni2013 = Rp. 11.128.750,00+ Rp. 417.534,24 (12)

$=$ Rp. $11 \cdot 128 \cdot 750,00+$ Rp. 5.010.410,88

$=$ Rp. $16 \cdot 139 \cdot 160,88$

Yjuli2013 = Rp. 11.128.750,00+Rp. 417.534,24 (13)

$=$ Rp. $11 \cdot 128 \cdot 750,00+$ Rp. 5.427.945,12

$=$ Rp. 16.556.695,12

Yagustus2013 = Rp. 11.128.750,00 + Rp. 417.534,24 (14)

$=$ Rp. 11.128.750,00 + Rp. 5.845.479,36

$=$ Rp. 16.974.229,36

Ysept2013

$=$ Rp. 11.128.750,00+Rp. 417.534,24 (15)

$=$ Rp. 11.128.750,00 + Rp. 6.263.013,60

$=$ Rp. 17,391,763.60 
Yoktober2013 = Rp. 11.128.750,00+ Rp. 417.534,24 (16)

$=$ Rp. $11 \cdot 128.750,00+$ Rp. $6 \cdot 680.547,84$

$=$ Rp. 17.809.297,84

Ynov2013 = Rp. 11.128.750,00+Rp. 417.534,24 (17)

$=$ Rp. 11.128.750,00 + Rp. 7.098.082,08

$=$ Rp. 18.226.832,08

Ydes2013 = Rp. 11.128.750,00+Rp. 417.534,24 (18)

$=$ Rp. 11.128.750,00 + Rp. 7.515.616,32

$=$ Rp. 18.644.366,32

Berdasarkan perhitungan yang menggunakan analisis metode kuadrat terkecil tejadi peningkatan setiap bulannya. Dimana biaya pemeliharaan mesin pada bulan januari 2013 sebesar Rp.14,051,489.68. Hingga pada bulan desember 2013 sebesar mencapai Rp. 18.644.366,32.

\section{Kesimpulan}

\section{PENUTUP}

Kesimpulan dari penelitian ini adalah dalam menggunakan analisis tiga selisih, didapati bahwa perusahaan mendapatkan selisih menguntungkan untuk biaya pemeliharaan mesin tetap yaitu pada selisih efisiensi karena unit yang diproduksi yaitu $1.750 .000 \mathrm{~kg}$ lebih besar dari unit yang direncanakan yaitu sebesar $1.166 .415 \mathrm{~kg}$.

\section{Saran}

Saran dari penelitian ini adalah perusahaan bisa menggunakan analisis varian untuk pengendalian biaya agar dapat mengetahui seberapa jauh selisih aktual dengan selisih yang direncanakan.

\section{DAFTAR PUSTAKA}

Artiningrum, Nurochmani. 2003. Evaluasi perencanaan dan pengendalian biaya pemeliharaan aktiva tetap (mesin) pada PG. Krebet Baru Bululawang. Skripsi Unikom. Bandung.

Carter, Wiliam. K., Milton, F, Usry. 2009. Akuntansi Biaya. Salemba Empat, Jakarta

Dharmanegara Ida Bagus Agung. 2010. Penganggaran Perusahaan Teori dan Aplikasi. Graha Ilmu. Yogyakarta.

Mulyadi. 2009. Akuntansi Biaya. UPP-Sekolah Tinggi Ilmu Manajemen YKPN.Yogyakarta

Mursyidi. 2007. Akuntansi Biaya (Convertion Costing, Just in Time, dan Activity-Based Costing). Refika Aditama. Bandung

Nafirin,M. 2007. Penganggaran Perusahaan. Salemba Empat. Jakarta

Prawironegoro Darsono., Purwanti Ari. 2008. Akuntansi Manajemen. Mitra Wacana Media. Jakarta.

Setiawan, F.D. 2008. Perawatan Mekanikal Mesin Produksi. Maximus. Yogyakarta.

Widilestarinigtyas Ony., Sony W.F., dan Anggadhini Sri Dewi. 2010. Akuntansi Biaya. Graha Ilmu.Yogyakarta.

Wijayanti, Finis. 2008. Analisis perencanaan dan pengendalian biaya pemeliharaan mesin dan instalasi pada PG.

Kebon Agung. Skripsi Universitas Muhamadiyah. Malang. 